\title{
Perfiles lipídico y proteico en plasma de yeguas de raza cuarto de milla en diferentes etapas reproductivas
}

\author{
Márquez, A. ${ }^{\text {; }}$ De Abreu, J.C. ${ }^{2}$; Márquez, Y.C. ${ }^{1}$; López, A. ${ }^{1}$ \\ ${ }^{1}$ Unidad de Investigación en Ciencias Funcionales Dr. "Haity Moussatché", ${ }^{2}$ Área de Producción de Equinos, \\ Facultad de Ciencias Veterinarias, Universidad Centroccidental "Lisandro Alvarado" (UCLA), \\ Barquisimeto, Venezuela. E-mail: adelism@ucla.edu.ve
}

\begin{abstract}
Resumen
Márquez, A.; De Abreu, J.C.; Márquez, Y.C.; López, A.A.: Perfiles lipídico y proteico en plasma de yeguas de raza cuarto de milla en diferentes etapas reproductivas. Rev. vet. 25 : 1, 54-57, 2014. Con el objetivo de conocer las variaciones de los perfiles lipídico y proteico en tres estadios reproductivos de yeguas de raza cuarto de milla (no gestantes, gestantes y lactantes), se estudiaron diez animales pertenecientes a un haras del estado Lara, Venezuela. Mediante punción yugular se obtuvo plasma anticoagulado con EDTA y por espectrofotometría se determinaron las concentraciones de triglicéridos (TG), colesterol total (CT) y colesterol ligado a lipoproteínas de alta y baja densidad (Col-HDL y Col-LDL), así como de proteínas totales (PT), albúmina (AL) y globulinas (GL). Los resultados señalaron disminuciones significativas $(\mathrm{p}<0,01)$ de los niveles plasmáticos de CT y Col-HDL en los estadios de gestación y lactancia, así como aumentos significativos de PT y GL en yeguas gestantes, en contraste con no gestantes y lactantes. Se postula que tales variaciones responden a las demandas metabólicas y hormonales propias de cada estadio reproductivo.
\end{abstract}

Palabras clave: yegua, lípidos, proteínas, estadio reproductivo.

\begin{abstract}
Márquez, A.; De Abreu, J.C.; Márquez, Y.C.; López, A.A.: Lipid and protein plasma profiles in quarter horse mares in different reproductive periods. Rev. vet. 25: 1, 54-57, 2014. In order to identify changes in lipid and protein profiles in three reproductive stages of quarter horse mares (non-pregnant, pregnant and lactating), ten animals from a stud farm in Lara State, Venezuela, were studied. Anticoagulated plasma with EDTA was obtained by jugular puncture. Concentration of triglycerides (TG), total cholesterol (TC), and cholesterol linked to high and low density lipoproteins (HDL-Col and LDL-Col), as well as total protein (TP), albumin (AL) and globulins (GL) were determined by spectrophotometry. Results showed significant decreases $(\mathrm{p}<0.01)$ in plasma levels of TC and HDL-Col during pregnancy and lactation, as well as significant increases in TP and GL in pregnant mares in contrast to non-pregnant and lactating ones. It is hypothesized that such variations resulted from the metabolic and hormonal demands of each reproductive stage.
\end{abstract}

Key words: mare, lipids, proteins, reproductive period.

\section{INTRODUCCIÓN}

A pesar de no ser considerado un atleta de elite como el pura sangre de carrera, el caballo cuarto de milla posee la carga genética propia de un animal atlético, muy bien balanceado en sus características de altura, longitud y profundidad de cuerpo, a lo que se suma una condición psicológica favorable por su buena disposición y rápido aprendizaje ${ }^{15,16,18,24}$. Esta raza se originó en la norteamérica colonial del siglo XVII, cuando los españoles trajeron sus caballos árabes y berberiscos al

Recibido: 11 marzo 2014 / Aceptado: 21 abril 2014 nuevo mundo, en tanto que las primeras colonias inglesas que se asentaron en Virginia, Carolina del Norte y del Sur, importaron sus caballos pura sangre. Al cruzar las razas orientales de los españoles y los pura sangre ingleses con otras razas como el percherón, se originó un caballo compacto y musculoso que podía correr distancias cortas más rápido que los pertenecientes a otras razas, de ahí su denominación de "cuarto de milla".

En Venezuela es un caballo popular entre los ganaderos, quienes lo aprecian por su velocidad, inteligencia, equilibrio y agilidad, virtudes que lo hacen excelente para el trabajo con el ganado, ya que es capaz de parar y girar sobre sí mismo con gran rapidez, aunque 
venga de un galope tendido, una cualidad que hoy en día se puede admirar en las competencias de las diferentes disciplinas de la monta western, trabajo y paseo.

Estos antecedentes explicarían la alta demanda metabólica de esta raza, en donde los lípidos juegan un papel central en la formación de membranas, síntesis de hormonas esteroides, aporte y transporte de combustible metabólico, entre otras. A este respecto se ha reportado que el aumento y composición de los lípidos circulantes en sangre de las yeguas, dependen de un gran número de variables fisiológicas, entre las cuales se pueden citar la naturaleza de la dieta, edad, estado reproductivo y de lactación ${ }^{5}$. Desde el punto de vista reproductivo, las concentraciones plasmáticas de colesterol y lipoproteínas han sido asociadas con la fertilidad, debido a que el colesterol es el precursor de la esteroidogénesis en todos los tejidos que secretan hormonas esteroides ${ }^{26}$.

Por su parte, las proteínas sanguíneas son de vital importancia para la homeostasis celular, así como para el desarrollo de los tejidos y músculos del feto. Mantener la concentración normal de proteínas totales en el plasma es necesario para el óptimo funcionamiento del metabolismo de la célula, así como para el transporte de ácidos grasos y hormonas ${ }^{17}$.

En caballos de salto se han demostrado variaciones del perfil metabólico posteriores al período de trabajo, con un aumento significativo del nivel de proteínas totales y albúmina en muestras de sangre. También se verificaron aumentos significativos de las concentraciones de lipoproteínas y colesterol total a los 60 minutos posteriores al ejercicio de salto ${ }^{25}$, sin embargo, no hubo diferencias entre los valores de proteínas totales de reposo y post ejercicio en equinos de la raza Holsteiner ${ }^{14}$.

Para los criadores de caballos cuarto de milla, así como para los veterinarios dedicados a la actividad hípica, es importante disponer de valores bioquímicos sanguíneos de referencia, no sólo para configurar las características fisiológicas específicas, sino para operar como base de datos necesarios para la interpretación de los hallazgos clínicos y para la realización de investigaciones experimentales, así como para establecer valores de referencias entre animales de la misma especie en diferente fase funcional, en distintos ambientes o sometidos a distintos tipo de manejo ${ }^{20}$.

Debido a la insuficiente información que existe en Venezuela sobre este tema, se realizó la presente investigación con el objetivo de determinar el perfil lipídico y proteico en yeguas de la raza cuarto de milla en tres estadios reproductivos: no gestantes, gestantes y lactantes.

\section{MATERIAL Y MÉTODOS}

Localización: La investigación fue realizada en un haras, ubicado en la población de Cordero, Municipio Iribarren, Estado Lara, Venezuela, localizado a una distancia de $25 \mathrm{~km}$ de Barquisimeto. La región po- see un clima cálido, con temperatura media anual de $26,4^{\circ} \mathrm{C}$ (amplitud de $21,5^{\circ} \mathrm{C}$ a $31,4^{\circ} \mathrm{C}$ ), humedad relativa del $78 \%$ y precipitación media anual de $1.050 \mathrm{~mm}$, características del bosque seco tropical de acuerdo a la clasificación de Holdridge ${ }^{11}$.

Población y muestra: Las yeguas incluidas en este estudio pertenecían a una población de hembras de la raza cuarto de milla registradas en la American Quarter Horse Association (AQHA). Se seleccionaron al azar, mediante un muestreo aleatorio simple, 10 yeguas adultas clínicamente sanas, de 2 a 5 partos. Al inicio del estudio fueron diagnosticadas no gestantes por palpación rectal, etapa que luego continuó con el período de gestación y finalizó al concluir la lactancia.

\section{Definición de cada estadio reproductivo}

Estado de no gestación: 60 días antes del inicio de la temporada de monta.

Estado de gestación: segundo tercio de la preñez.

Estado de lactancia: 90 días postparto

Manejo y toma de muestra: Las yeguas fueron sometidas al mismo manejo, incluido plan de alimentación y sanitario de acuerdo a los lineamientos de producción del haras, donde se emplea un sistema totalmente intensivo. En cada período reproductivo, sin lapso previo de ayuno, las yeguas fueron sometidas a extracciones de sangre con anticoagulante EDTA-Na al $1 \%$, mediante punción (Vacutainer) de la vena yugular con aguja calibre 21, realizada entre las 8:00 am a 10:00 am. Las muestras se transportaron al laboratorio refrigeradas a $4^{\circ} \mathrm{C}$ en tubos plásticos de centrífuga, siendo inmediatamente centrifugadas a $700 \mathrm{G}$ x $20 \mathrm{~min}$. Separado el plasma, se mantuvo a $4^{\circ} \mathrm{C}$. y se realizó la cuantificación de lípidos y proteínas.

Perfil lipídico: En los plasmas se determinó la concentración de triglicéridos (TG) por método enzimático ${ }^{19}$ mediante kit Qualitest (Caracas, Venezuela) con un patrón de $200 \mathrm{mg} / \mathrm{dl}$ de trioleína. La lectura de la absorbancia del producto coloreado se realizó a una longitud de onda de $500 \mathrm{~nm}$ en un espectrofotómetro Genesys 5 (Rochester, NY, USA). Las concentraciones de colesterol total (CT) y sus fracciones contenidas en las lipoproteínas de alta densidad (Col-HDL) y baja densidad (Col-LDL), se determinaron por método enzimático ${ }^{1}$ a través del kit Colestat de Wiener Lab (Rosario, Argentina), en el fotómetro mencionado ut supra, a $505 \mathrm{~nm}$. La concentración de los lípidos se expresó en $\mathrm{mg} / \mathrm{dl}$.

Perfil proteico: La determinación de proteínas totales (PT) y las fracciones albúmina (AL) y globulinas (GL) se realizaron por método colorimétrico ${ }^{22}$ mediante kit Proti-2 de Wiener Lab (Rosario, Argentina) con patrones de 4,8 g/dl de PT y 2,9 g/dl de AL. La lectura de la absorbancia de las primeras se realizó a una longitud de onda de $540 \mathrm{~nm}$ y de las segundas a $625 \mathrm{~nm}$, 
en ambos casos en el espectrofotómetro antemencionado. Los valores se expresaron en $\mathrm{g} / \mathrm{dl}$ y las GL fueron calculadas por diferencia de las dos concentraciones anteriores.

Diseño experimental y análisis estadístico: Esta investigación a campo enmarcó dentro de un diseño experimental completamente aleatorizado. Los resultados obtenidos fueron procesados estadísticamente con auxilio del programa SPSS versión 17.0 para Windows y se expresaron en media aritmética \pm error estándar $(\overline{\mathrm{x}} \pm \mathrm{EE})$. La significación de las diferencias se estimó por análisis de varianza a una vía. Las diferencias entre medias se determinaron mediante la prueba de Tukey, exigiéndose un $95 \%$ de certeza $(\mathrm{p}<0,05)$.

\section{RESULTADOS Y DISCUSIÓN}

Perfil Lipídico. En este estudio, la inclusión de los lípidos se justificó por las importantes funciones que cumplen en el organismo, tales como almacenamiento de combustible metabólico, transporte de este combustible, aislamiento protectivo y componente estructural de membranas y submembranas ${ }^{6}$. De allí la importancia de conocer el estatus lipídico en yeguas en diferentes estadios fisiológicos.

En la Figura 1 se presenta la concentración plasmática de CT total y sus fracciones en las yeguas cuarto de milla estudiadas. Se constataron disminuciones significativas $(\mathrm{p}>0,01)$ de CT y Col-HDL en los estadios de gestación y lactancia, al compararlos con los valores obtenidos en hembras no gestantes. Ello respondería a la mayor demanda de estos componentes lipídicos sanguíneos durante las etapas reproductivas indicadas, en las cuales se eleva la exigencia de colesterol para la formación de progesterona; en este sentido ha sido determinado en bovinos que las HDL son las principales fuentes de este metabolito ${ }^{3}$.

Nuestros resultados coinciden con los registrados en bovinos por otros investigadores, quienes aseveran que la concentración de colesterol sérico está significativamente influenciada por el parto y por la condición de lactación ${ }^{26}$. En contraposición, en otro trabajo no

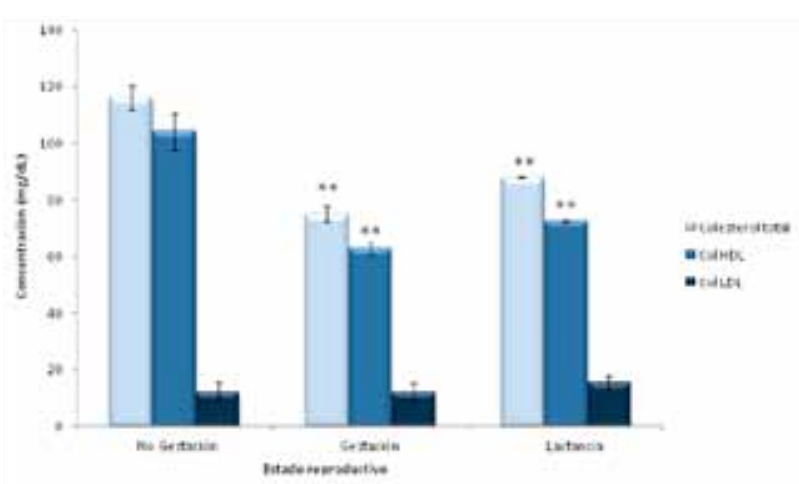

Figura 1. Concentraciones de CT, Col-HDL y ColLDL según estadio reproductivo de las yeguas $(n=10$, $\overline{\mathrm{x}} \pm \mathrm{EE}$ ). ${ }^{* *} \mathrm{p}<0,01$ respecto al estadio de no gestación.

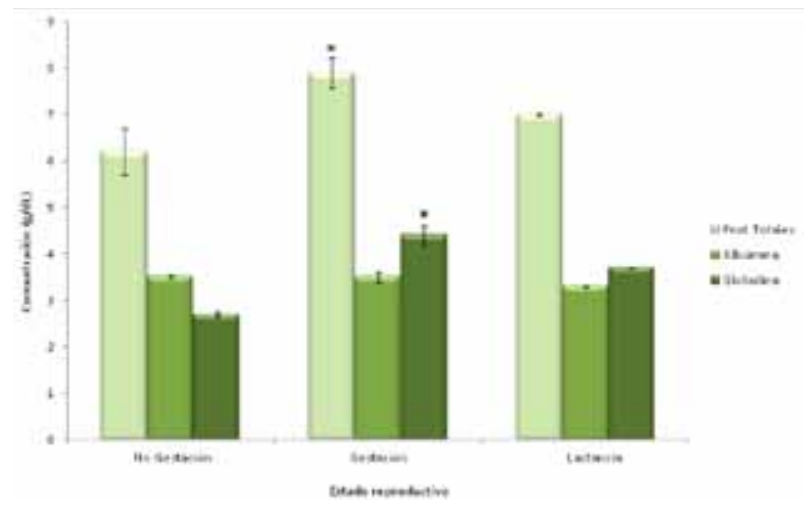

Figura 2. Concentraciones de PT, AL y GL según estadio reproductivo de las yeguas. $(\mathrm{n}=10, \overline{\mathrm{x}} \pm \mathrm{EE})$. ${ }^{*} \mathrm{p}<0,01$ respecto al estadio de no gestación.

pudieron demostrarse modificaciones lipídicas, durante la gestación y lactación en bovinos ${ }^{21}$. Es importante recordar que el caballo, como la mayoría de los mamíferos, es una especie animal cuya principal fracción lipoproteica es la HDL ${ }^{4}$ ("patrón HDL"), lo que queda evidenciado en la Figura 1 en cada una de las condiciones reproductivas estudiadas.

Los resultados obtenidos en la presente investigación muestran que en la lactancia los valores del ColLDL revelaron una tendencia al aumento $(15,4 \pm 2,8 \mathrm{mg} /$ dl) que no alcanzó significación estadística en relación a la etapa no gestante $(12,2 \pm 3,30 \mathrm{mg} / \mathrm{dl})$ (Figura 1). En vacas lecheras la concentración de Col-LDL ha sido relacionada con la lactancia pues los valores plasmáticos aumentan a medida que avanza dicho estadio ${ }^{13}$. Es sabido que hacia el final de la gestación la elevación de los estrógenos induce un aumento de los receptores de LDL con disminución de la concentración plasmática de la lipoproteína, pero una vez ocurrido el parto los estrógenos disminuyen con subsecuente reducción de los receptores de LDL y elevación de la concentración plasmática de LDL.

Por su parte los TG plasmáticos no mostraron diferencias significativas entre los estadios reproductivos estudiados. Sus niveles fueron de 22,6 $\pm 2,02 \mathrm{mg} / \mathrm{dl}$ en no gestantes, $25,2 \pm 1,54 \mathrm{mg} / \mathrm{dl}$ en gestantes y $23,3 \pm 0,24$ $\mathrm{mg} / \mathrm{dl}$ durante la lactancia. Cabe señalar que los valores de TG hallados en esta investigación se ubican en el rango de concentración reportado en caballos de raza criolla venezolana ${ }^{23} \mathrm{y}$ en yeguas peruanas de paso ${ }^{7}$.

En el presente estudio se observó una tendencia al incremento de la concentración de TG en las yeguas en etapa de gestación, aunque no alcanzó significación estadística. Dado que el ensayo se realizó durante el segundo trimestre de gestación, no se descarta que en el último tercio de la preñez el aumento de TG plasmáticos sea más evidente, tal como ha sido reportado por otros autores en la gestación avanzada de la yegua ${ }^{8}$.

Perfil Proteico. Las proteínas plasmáticas realizan funciones de nutrición, ejercen presión coloidosmótica 
y ayudan al mantenimiento del equilibrio ácido-base. Además, operan como enzimas, factores de coagulación, hormonas y sustancias de transporte ${ }^{10}$. Los valores plasmáticos obtenidos para $\mathrm{PT}$ y sus fracciones $\mathrm{AL}$ y GL se ubicaron dentro del rango observado para otras razas equinas ${ }^{9,12}$, aunque resultaron menores a los reportados para el caballo criollo venezolano ${ }^{2}$.

En la Figura 2 se presentan los valores del perfil proteico de las yeguas cuarto de milla aquí estudiadas. En las hembras no gestantes los valores plasmáticos obtenidos fueron de $6,2 \pm 0,05 \mathrm{~g} / \mathrm{dl}$ para PT, de $3,5 \pm 0,05 \mathrm{~g} /$ dl para AL y de $2,7 \pm 0,05 \mathrm{~g} / \mathrm{dl}$ para GL. Tanto PT como GL fueron significativamente más altas $(p<0,05)$ durante la gestación $(7,9 \pm 0,32 \mathrm{~g} / \mathrm{dl}$ y $4,4 \pm 0,21 \mathrm{~g} / \mathrm{dl}$, respectivamente), en contraste con los otros dos períodos reproductivos estudiados. El aumento de las globulinas plasmáticas durante la gestación está relacionado a la necesidad de aumentar los anticuerpos maternos con fines de asegurar una adecuada inmunidad pasiva a la cría. Como consecuencia de la elevación de las globulinas se produjo un aumento en la concentración total de las proteínas, en el estadio de gestación.

En conclusión, se establece que en las yeguas cuarto de milla hubo disminuciones significativas de los niveles plasmáticos de CT y Col-HDL, en los estadios de gestación y lactancia, lo que responde a las demandas metabólicas y hormonales propias de estos estados reproductivos. Durante la gestación, los parámetros proteicos mostraron aumentos significativos de GL y consecuentemente de PT plasmáticas, debido a la necesidad de aumentar los anticuerpos maternos para asegurar una adecuada inmunidad pasiva a la cría.

\section{REFERENCIAS}

1. Allain CC, Poon LS, Chan CS, Richmond W, Fu PC. 1974. Enzymatic determination of total serum cholesterol. Clin Chem 20: 470-475.

2. Bravo M, Matheus N, Canelón J, Vargas B, Páez J. 2004. Perfil proteico del caballo criollo venezolano según la edad, sexo y época del año. Gaceta Cs Vet 10: 93-97.

3. Borges AM, Torres CA, Ruas JR, Carvalho GR, Rocha VR. 2001. Concentração plasmática de colesterol total e lipoproteína de alta densidade em novilhas mestiças doadoras de embriões tratadas com somatotropina bovina recombinante. Arq Bras Med Vet Zootec 53: 605-610.

4. Chapman MJ. 1986. Comparative analysis of mammalian plasma lipoproteins. Methods Enzymol 128: 70-143.

5. Christie WW. 1981. The composition, structure and function of lipids in the tissues of ruminant animals. In: Lipid metabolism in ruminant animals (Moore JH ed.), Pergamon Press, Oxford (UK), $452 \mathrm{p}$.

6. Coppo NB, Coppo JA, Lazarte MA. 2003. Intervalos de confianza para colesterol ligado a lipoproteínas de alta y baja densidad en suero de bovinos, equinos, porcinos y caninos. Rev Vet 14: 1-8.

7. Díaz C, Plaza E, Chimoy E. 2008. Niveles séricos de triglicéridos y colesterol en caballos peruanos de paso bajo dos sistemas de crianza. Rev Inv Perú 19: 134-139.
8. Dunkel B, McKenzie H. 2003. Severe hypertriglyceridaemia in clinically ill horses: diagnosis, treatment and outcome. Equine Vet J 35: 590-595.

9. Eades S, Bounous D. 1997. Laboratory Profiles of Equine Diseases, Mosby, St. Louis (USA), p. 5-6.

10. Evans E, Duncan R. 2005. Proteínas, lípidos y carbohidratos. En: Patología Clínica Veterinaria (Latimer K ed.), Multimédica Ed Vet, Barcelona, p. 199-235.

11. Ew JJ, Arnold M, Tosi JP. 1976. Zonas de vida de Venezuela. Memoria explicativa sobre el mapa ecológico, $2^{\circ}$ ed., Edit. Sucre, Caracas, p. 76-88.

12. Ferraro S, Márquez A. 2001. Perfil proteico y lipídico en yeguas "paso fino" adultas. Acta Cientif Venez 52: 270-271.

13. Galvis RD, Agudelo D, Saffon A. 2007. Condición corporal, perfil de lipoproteínas y actividad ovárica en vacas Holstein en lactancia temprana. Rev Col Cienc Pec 20: 1629.

14. Gómez C, Petrón P, Andaur M, Pérez R, Matamoros R. 2004. Medición post-ejercicio de variables fisiológicas, hematológicas y bioquímicas en equinos de salto Holsteiner. Rev Cient FCV-LUZ, 14: 244-253.

15. Gunn HM. 1986. A perspective an athletic ability. Irish Vet. J 40: 85-86.

16. López JL. 1993. Histochemical, biochemical and morphological characteristic of skeletal muscle of horse. $\mathrm{Ag}$ roCiencia 9: 113-131.

17. Matheus N, Ramírez F, Salazar C, Leonardi F, Bravo H. 2001. Relación albúmina/globulina plasmáticas en tres épocas del año en vacas de la raza Carora del Estado Lara, Venezuela. Gaceta Cs Vet 7: 4-10.

18. McMiken DF. 1986. Muscle-fiber types and horse performance. Equine Pract 8: 6-15.

19. Patton JG, Dinh DM, Mao SJ. 1982. Phospholipid enhances triglyceride quantitation using an enzyme kit method. Clin Chem Acta 118: 125-128.

20. Ramírez LL, Azuaje KK, Sánchez F, Díaz A. 1999. Observaciones hematológicas en búfalos de agua (Bubalus bubalis) aparentemente sanos en el occidente de Venezuela. Rev Cient FCV-LUZ 9: 524-531

21. Raphael B, Dimick, P. 1973. Characterization of bovine serum proteins throught gestation and lactation. J Dairy Sci 56: 1025.

22. Rojkin ML, Olguin DE, Mariani MC, Drappo GA, Sosa CP. 1974. Proteínas totales del suero: causas mas frecuentes de error en la reacción de Biuret. Nuevo reactivo cuproalcalino estable. Bioq Atlánt 5: 1163-1193

23. Rossini M, Zerpa H. 2004. Valores hematológicos del caballo criollo venezolano. Acta Cient Venez 55: 1.

24. Snow DH. 1985. The horse and dog, elite athletes-why and how. Proc Nutrit Soc 44: 267-272.

25. Stevanovic J, Vitic J. 1996. Some proteins, lipoprotein and lipid alteration in serum of show jumping horses during different phases of training. Acta Vet 46: 2-3.

26. Talavera F, Park CS, Williams GL. 1985. Relationships among dietary lipid intake, serum cholesterol and ovarian function in Holstein heifers. J Anim Sci 60: 1045-1054. 